\title{
CHANGES IN RENAL FUNCTION TEST FOLLOWING KIDNEY DONATION
}

\author{
MOHAMMED MIZANUR RAHMAN ${ }^{1}$, PROBIR KUMAR ROY ${ }^{2}$, MH RAHMAN², TMS HOSSAIN², \\ MD WALIUL ISLAM ${ }^{3}$, LUTFA BEGUM LIPI ${ }^{4}$, SUDIP DAS GUPTA ${ }^{1}$
}

${ }^{1}$ Department of Urology, Sir Salimullah Medical College, Dhaka, 2Department of Urology, Bangabandhu Sheikh Mujib Medical University,Dhaka, ${ }^{3}$ Department of Urology, National Institute of Kidney Diseases \&Urology,Dhaka, ${ }^{4}$ Department of Urology, Dhaka Medical College Hospital,Dhaka, ${ }^{5}$ Department of Urology, National Institute of Preventive \& Social Medicine,(NIPSOM), Dhaka

\begin{abstract}
:
Objectives: The aim of this study was to find out any Changes in renal function test following kidney donation.

Materials and Methods: A Hospital based prospective study was conducted in the Department of Urology of Bangabandhu Sheikh Mujib Medical University, Dhaka, Bangladesh from April 2011 to September 2012. Investigations included specific gravity and urinary microalbumin, serum creatinine. According to inclusion and exclusion criteria a total of 37 donors were enrolled in this study. Subsequent follow up were taken at the end of three months, six months and nine months. Data were evaluated by Paired t-test, Significance was defined $p$ value $<0.05$.

Results: The age range varied from 25 to 39 years and $45.9 \%$ of patients belonged to 25 30 years and male to female ratio was 1:2.4. The mean baseline specific gravity was $1016.97 \pm 8.03$, serum creatinine $1.03 \pm 0.24$. The baseline urinary micro albumin was found nil and subsequent $1^{\text {st }}, 2^{\text {nd }}$, and $3^{\text {rd }}$ follow up were also nil. The mean difference of specific gravity, urinary micro albumin, and serum creatinine $(\mathrm{mg} / \mathrm{dl})$ were almost consistent between baseline and the subsequent follow-up, no statistical significant $(P>0.05)$ was found between baseline and the subsequent follow-up.
\end{abstract}

Conclusion: Renal function test of the remaining kidney in living donors does not significantly change after donor nephrectomy.

Key words: Kidney donation, Renal Function,

\section{Introduction}

Kidney transplantation is a standard treatment for patients with end-stage renal disease and which confers a survival benefit and is cost effective compared with haemodialysis. Living kidney donation is the main source in many countries, because the outcomes of cadaver transplantations are poor[1].

The inadequate supply of deceased donor kidneys is one of the factors to increase the number of living donor kidney transplants. The advantages of living donor renal

Correspondence: Mohammed Mizanur Rahman, Department of Urology,Sir Salimullah Medical College \& Mitford Hospital, Email: mizan_1616@yahoo.com transplantation compared with deceased donor renal transplantation are better for graft survivals, less recipient morbidity, specific planning of the operation.

Renal function is thoroughly evaluated before live kidney donation. Potential kidney donors are also evaluated before donation. However, owing to increased demand for organs, some kidney transplant centers are becoming more willing to accept the living donors with regard to increase age, obesity, or low/normal glomerular filtration rate[2].

Living donor kidney transplantation provides superior allograft function for the recipients with a low risk of complications such as hypertension and chronic kidney disease for donors[3]. 
Studies after live donor nephrectomy suggest that the long-term risk to the donor of developing end-stage renal disease is similar to the general population. The longterm safety of nephrectomy depends on careful screening to identify healthy donors with excellent renal function and a low likelihood of developing progressive disease in the remaining kidney[4].

Live donor kidney transplantation has excellent result for patient and graft survival with advances in immunesuppression and medical management.Follow-up studies of the live donors indicate that kidney donation is currently a safe procedure with low morbidity and mortality[5].

The major reasons leading to improved outcomes are more potent due to selective immunosuppression, better surgical techniques, more sensitive cross-matching and better prophylaxis and treatment of morbid infections. There is also an emerging consensus that preemptive transplantation, immediately prior to the need to dialysis, is advantageous in reducing morbidity and mortality[6].

The present study is designed to find out any Changes of renal function test following unilateral kidney donation.

\section{Materials and methods}

A Hospital based prospective study was conducted in the Department of Urology of Bangabandhu Sheikh Mujib Medical University, Dhaka, Bangladesh from April 2011 to September 2012, to find out Changes of renal function test following kidney donation in whom renal functions were within normal limit prior to donation. History, clinical examinations and investigations are necessary to identify the potential complications and outcomes. Investigations were included specific gravity from routine microscopic examination of urine and serum creatinine. Inclusion criterion for the present study was - all donors who were suitable for kidney donation and exclusion criterion was those who did not give consent to enter into this study. According to inclusion and exclusion criteria a total of 37 donors were enrolled in this study. Then purposive sampling was applied to collect sample from all kidney donors or participants by inclusion and exclusion criteria. By seeing the dependent variable of donors from investigations reports which were done in the various government hospitals or recognised private clinics. In analyzer machine, serum creatinine was estimated by enzymatic method using picric acid containing reagent. Total 37 donors were collected by this technique in our study period.
Subsequent follow up were taken at the end of three months, six months and nine months following nephrectomy

1) Specific gravity from routine microscopic examination of urine

2) Micro albumin from examination of urine

3) Serum creatinine

\section{Result}

A total of 37 Donors were included in this study. Majority number of Donors were found belonged to 25-30 years. The mean age was found $31.41 \pm 3.99$ years with range from 25 to 39 years. Male was found $29.7 \%(11)$ and female was $70.3 \%(26)$. Male female ratio was 1:2.4. (Table I).

Table I

Age and sex distribution of the respondents( $n=37)$.

\begin{tabular}{lcc}
\hline & Number of Donor & Percentage \\
\hline Age (in years) & 17 & \\
$25-30$ & 12 & $45.9 \%$ \\
$31-35$ & 8 & $32.4 \%$ \\
$36-40$ & 31.41 & \pm 3.99 \\
Mean \pm SD & $(25$ & $-39)$ \\
Range (min-max) & & \\
Sex & 11 & $29.7 \%$ \\
Male & 26 & $70.3 \%$ \\
Female &
\end{tabular}

Table II shows the specific gravity of the urine to assess the renal function. Before transplant the mean specific gravity of urine was found $1016.97 \pm 8.03,1^{\text {st }}$ follow up specific gravity was $1014.02 \pm 6.57,2^{\text {nd }}$ follow specific gravity was $1017.4 \pm 6.9$ and $3^{\text {rd }}$ follow up specific gravity was $1015.64 \pm 5.75$. The difference was not statistically significant $(P>0.05)$ between different follow up in paired t-test. The mean of serum creatinine (Table III) before transplant was found $1.03 \pm 0.24,1^{\text {st }}$ follow up serum creatinine was $0.96 \pm 0.22,2^{\text {nd }}$ follow up serum creatinine was $1.09 \pm 0.22$ and $3^{\text {rd }}$ follow up serum creatinine was $1.0 \pm 0.21$. The difference was not statistically significant $(P>0.05)$ between different follow up in paired t-test.

Table IV shows estimation of renal function by microalbumin of urine. The baseline microalbumin of urine was found nil and subsequent $1^{\text {st }}, 2^{\text {nd }}$, and $3^{\text {rd }}$ follow up did not show significant change. 
Table II

Distribution of respondents according to specific gravity $(n=37)$

\begin{tabular}{lcccc}
\hline Specific Gravity & Mean \pm SD & (Min & - max $)$ & $P$ \\
\hline Before transplant & $1016.97 \pm 8.03$ & $(1003$ & $-1029)$ & value \\
$1^{\text {st }}$ follow up at the end of 3 months & $1014.02 \pm 6.57$ & $(1003.17$ & $-1025.15)$ & $0.088^{\text {ns }}$ \\
$2^{\text {nd }}$ follow up at the end of 6 months & $1017.4 \pm 6.9$ & $(1006.36$ & $-1027.9)$ & $0.805^{\text {ns }}$ \\
$3^{\text {rd }}$ follow up at the end of 9 months & $1015.64 \pm 5.75$ & $(1006.02$ & $-1025.58)$ & $0.415^{\text {ns }}$ \\
\hline
\end{tabular}

Table III

Distribution of respondents according to serum creatinine ( $n=37)$

\begin{tabular}{lccccc}
\hline Serum creatinine $(\mathrm{mg} / \mathrm{dl})$ & Mean & \pm SD & (Min & - max $)$ & P value \\
\hline Before transplant & 1.03 & \pm 0.24 & $(0.6$ & $-1.4)$ & \\
$1^{\text {st }}$ follow up at the end of 3 months & 0.96 & \pm 0.22 & $(0.6$ & $-1.4)$ & $0.195 \mathrm{~ns}$ \\
$2^{\text {nd }}$ follow up at the end of 6 months & 1.09 & \pm 0.22 & $(0.7$ & $-1.4)$ & $0.266 \mathrm{~ns}$ \\
$3^{\text {rd }}$ follow up at the end of 9 months & 1.0 & \pm 0.21 & $(0.6$ & $-1.4)$ & $0.569 \mathrm{~ns}$ \\
\hline
\end{tabular}

Table IV

Distribution of respondents according tomicroalbumin of urine $(n=37)$

\begin{tabular}{lccc}
\hline Microalbumin of urine & Findings & Number of patients & Percentage \\
\hline Baseline & Nil & 37 & $100 \%$ \\
$1^{\text {st }}$ follow up at the end of 3 months & Nil & 37 & $100 \%$ \\
$2^{\text {nd }}$ follow up at the end of 6 months & Nil & 37 & $100 \%$ \\
$3^{\text {rd }}$ follow up at the end of 9 months & Nil & 37 & $100 \%$ \\
\hline
\end{tabular}

\section{Discussion}

In this current study it was observed that majority number of donor belonged to $25-30$ years and the mean age was $31.41 \pm 3.99$ years with range from 25 to 39 years. Similarly, Azar et al. showed the mean age at the time of donation was $28.97 \pm 4.75$ years with range from 18 to 47 years, which is comparable with the current study. In another study a higher mean age observed by Chien et al. where the investigators found mean age was 45 years with range from 23 to 68 years at the time of kidney donation. Freedland et al.[7] and Reese et al. found the mean age were $39.0 \pm 9.0$ years and $39 \pm 10$ years respectively at the time of donation. The higher age range may be due to increased life expectancy in their study donor. Younger donors exhibit a capacity for hyperfiltration that remains for several years, whereas renal function declines in the elderly.

In this current series it was observed that male and female donors were found $29.7 \%$ and $70.3 \%$ respectively, where male to female ratio was $1: 2.4$, which indicates that female donor is predominant. Similarly, Gossmann et al.[8] found 29.0\% male and $71.0 \%$ female. Similar observations regarding the female predominant donor were also made by Freedland et al. and Reese et al. On the other hand, Azar et al. showed male predominant, where the authors found $67.5 \%$ male and $32.5 \%$ female.

Hamza et al. [9] found that renal function parameters such as serum creatinine, showed a relevant increase between 12 and 18 hours after donor nephrectomy. The time to increase differed slightly between individual parameters. At day 4, there was no significant difference between the initial and final values, except urine $\alpha 1$ microglobulin, which indicates an impaired tubular function. In this study it was observed that the mean baseline serum creatinine was $1.03 \pm 0.24 \mathrm{mg} / \mathrm{dl}$ varied from $0.6-1.4 \mathrm{mg} / \mathrm{dl}$, 1st follow up it was $0.96 \pm 0.22 \mathrm{mg} /$ dl varied from $0.6-1.4 \mathrm{mg} / \mathrm{dl}$, 2nd follow up it 1.09 \pm 0.22 $\mathrm{mg} / \mathrm{dl}$ varied from $0.7-1.4 \mathrm{mg} / \mathrm{dl}$ and $3 \mathrm{rd}$ follow up it was $1.0 \pm 0.21 \mathrm{mg} / \mathrm{dl}$ varied from $0.6-1.4 \mathrm{mg} / \mathrm{dl}$. The mean 
difference was not statistically significant $(P>0.05)$ between different follow up, that indicates serum creatinine level were almost consistent during baseline and the subsequent follow-up, which are similar with Mjoen et al. and Nozaki et al. [10]. In another study Chien et al. [11] showed mean serum creatinine before kidney donation 0.90 with range from 0.58 to $1.40 \mathrm{mg} /$ dl; Day 2 after kidney donation it was 1.31 with range from 0.80 to $1.90 \mathrm{mg} / \mathrm{dl}$ and the mean change was +0.4 with varied from +0.1 to $+0.7 \mathrm{mg} / \mathrm{dl}$. In another study, Siebels et al.[12] obtained the mean $( \pm S D)$ Creatinine during pre-operative was $0.88 \pm 0.12 \mathrm{mg} / \mathrm{dl}$ and postoperative was $1.45 \pm 0.52 \mathrm{mg} / \mathrm{dl}$. Lind et al [13] reported that serum creatinine in laparoscopic donors was significantly greater than that in open-operation donors at 1 day, 3 months, and 1 year posttransplantation. However, most reports compared donor renal function with both kidneys before nephrectomy with that of the single nondonated kidney after nephrectomy. Such analysis can not demonstrate the actual functional change in the preserved kidney after Laparoscopic donor nephrectomy.

In this current study before transplant the albumin of urine was found nil and subsequent $1^{\text {st }}, 2^{\text {nd }}$, and $3^{\text {rd }}$ follow up were also nil. El-Agroudy et al. [14] and Ibrahim et al.[15] found similar findings in their study but ElAgroudy et al. found $3.4 \%$ albumin of urine in long time follow-up.

\section{Conclusion:}

This study demonstrates that renal function of the remaining kidney in living donors do not significantly change after donor nephrectomy.

Conflict of interest: None declared.

\section{References}

1. Azar SA, Nakhjavani MR, Tarzamni MK, Faragi A, Bahloli A \& Badroghli N. 'Is Living Kidney Donation Really Safe', Transplantation Proceedings, 2007; 39: 822-823.

2. Mjøen G, Øyen O, Midtvedt K, Dahle DO, Norby $\mathrm{G}$ \& Holdaas H 2011, 'Age, gender, and body mass index are associated with renal function after kidney donation', Clinical Transplantation, vol. 25 HYPERLINK "http://hinari-gw.who.int/whalecomonlinelibrary. wiley.com/whalecom0/doi/10.1111/ctr.2011.25. issue-6/issuetoc", HYPERLINK "http://hinarigw.who.int/whalecomonlinelibrary. wiley.com/ whalecom0/doi/10.1111/ctr.2011.25 .issue-6/ issuetoc"HYPERLINK "http://hinari-gw.who.int/
Changes in Renal Function Test Following Kidney Donation

whalecomonlinelibrary.wiley.com/whalecom0/doi/ 10.1111/ctr.2011.25.issue-6/issuetocpp. 579-583.

3. Henze A, Raila J, Kempf C, Reinke P, Sefrin A, Querfeld U, et al. 'Vitamin A metabolism is changed in donors after living-kidney transplantation: an observational study', Lipids Health Dis, 2011; 7: 231-237.

4. Reese PP, Simon MK, Stewart J \& Bloom JJ. 'Medical Follow-up of Living Kidney Donors by 1 Year After Nephrectomy', Transplantation Proceedings, 2009; 41: 3545-3550.

5. Bohlouli A, Tarzamni MK, Zomorodi A, Abdollahifard S, Hashemi B \& Nezami N. 'Remnant kidney function and size in living unrelated kidney donors after nephrectomy', Saudi J Kidney Dis Transpl, 2010; 21: 246-250.

6. Kasiske BL. Snyder JJ, Matas Aj. et al. Preemptive kidney transplantation: the advantage and the advantaged. J Am Soc Nephrol 2002; 13: 1358-64.

7. Freedland SJ, Blanco-Yarosh M, Sun JC, Hale SJ, Elashoff DA, Rajfer JA, et al. 'Effect of ketorolac on renal function after donor nephrectomy', Urology, 2002; 59: 826-830.

8. Gossmann J, Wilhelm A, Kachel HG, Jordan J, Sann U, Geiger $\mathrm{H}$ et al. 'Long-term consequences of live kidney donation follow-up in 93\% of living kidney donors in a single transplant center', Am J Transplant, 2005; 5: 2417-24.

9. Hamza A, Wagner S \& Weigand K. 'Transperitoneal, hand assisted laparoscopic donor nephrectomy: surveillance of renal function by immune monitoring', TransplProc, 2008; 40: 895-901.

10. Nozaki $\mathrm{T}$, Ishida $\mathrm{H}$, Tokumoto $\mathrm{T}$, Shirakawa $\mathrm{H}$, Shimizu T, Omoto K, et al. 'Risk Factors for Deterioration of Renal Function After Donor Nephrectomy', Transplantation Proceedings, 2010; 42: 1476-1478.

11. Chien $\mathrm{CH}$, Wang $\mathrm{HH}$, Chiang $\mathrm{YJ}$, Chu SH, Liu HE \& Liu KL. 'Change in Renal Function After Laparoscopic Donor Nephrectomy for Kidney Transplantation', Transplantation Proceedings, 2010; 42: 692-695.

12. Siebels M, Theodorakis J, Schmeller N, Corvin S, Burchardi NM, Hillebrand G, et al. 'Risks and 
Mizanur et al.

complications in 160 living kidney donors who underwent nephroureterectomy', Nephrol Dial Transplant, 2003; 18: 2648-2654.

13. Lind MY, Borg IMZ, Hazebroek EJ, Hop WCJ, Alwayn IPJ, Weimar W, et al. 'The effect of laparoscopic and open donor nephrectomy on the long-term renal function in donor and recipient: a retrospective study', Transplantation. 2005; 80: 700-703.
14. El-Agroudy AE, Wafa EW, Sabry AA, Neamatalla $A H$, Khalel AA, Isamil AM, et al. 'The health of elderly living kidney donors after donation', Ann Transplant, 2009; 14: 13-19.

15. Ibrahim HN, Foley R, Tan L, Rogers T, Bailey $\mathrm{RF}$, Guo $\mathrm{H}$, et al. 'Long-term consequences of kidney donation', N Engl J Med, 2009; 360: 459-69. 